\title{
Pathological or physiological erosion-is there a relationship to age?
}

\author{
David Bartlett • Chris Dugmore
}

Received: 8 June 2007 / Accepted: 18 December 2007 / Published online: 29 January 2008

(C) Springer-Verlag 2007

\begin{abstract}
This conventional literature review discusses whether pathological tooth wear is age dependant. It briefly reviews the components of tooth wear and the prevalence of tooth wear in children, adolescents and adults. The emphasis on terminology relating to tooth wear varies. In some countries, the role of erosion is considered the most important, whereas others consider the process to be a combination of erosion, attrition and abrasion often with one being more dominant. The importance of tooth wear or erosion indices in the assessment and the evidence for progression within subject and within lesions is described. The data from the few studies reporting pathological levels of wear reported in children and adults are discussed, in particular its relationship with age. There is little evidence to support the concept that pathological levels of erosion or wear are age dependant. There is, however, some evidence to suggest that normal levels of erosion or wear are age dependant.
\end{abstract}

Keywords Erosion - Tooth wear . Tooth wear index .

Attrition $\cdot$ Abrasion

This manuscript is submitted to the "Special Issue on Dental Erosion". The results of a conference supported by GABA held in Basel in April 2007.

D. Bartlett $(\bowtie)$

Department of Fixed and Removable Prosthodontics,

King's College London Dental Institute,

Floor 25, Guy's Tower, London Bridge,

SE19RT London, UK

e-mail: david.bartlett@kcl.ac.uk

C. Dugmore

Leicestershire County and Rutland PCT,

Pasley Road Health Centre, Eyres Monsell,

Leicester LE2 9BU, UK

\section{Introduction}

There has been considerable interest recently on the epidemiology and pathogenesis of dental erosion. Much of the epidemiology has been investigated in children and adolescents rather than adults and so the validity of any association between severity and age is based on clinical observations seen primarily in these young people $[1,3,7$, 17]. The aim of this paper is to consider and investigate the concept that pathological erosive tooth wear is age dependant.

There is some debate within the dental academic community on the appropriateness of terminology. Many academics recognise the term tooth wear as encompassing erosion, attrition and abrasion. However, other researchers focus upon acid erosion often using the term to describe what others would call tooth wear and use the term erosion in a context which others might not agree. Whilst the definitions of erosion, abrasion and attrition are accepted, the relative importance of these causes is not. Therefore, in this paper both terms are used where appropriate to convey meaning interpreted by many researchers working in this field.

\section{Tooth wear and erosion}

The causes of tooth wear are considered to be erosion, abrasion, attrition and possibly abfraction. Traditionally, erosion is associated with loss of enamel and dentine from acids either intrinsic [4] (gastric) or extrinsic (dietary) [29]. Abrasion is more commonly associated with wear from surfaces other than teeth, whereas attrition is wear from tooth to tooth contact [26]. Abfraction is a considered by some to be a component of tooth wear, but so far apart from 
some laboratory studies, there is little clinical evidence to provide support for its role [9].

However, different countries interpret the aetiologies in different ways [8]. Many European countries focus attention upon erosive tooth wear, whereas in North American countries, abrasion or attrition is more commonly recognised whilst the role of erosion is less understood. In the United Kingdom, although the importance of erosion is acknowledged, the impact of abrasion and attrition is also recognised, and the term tooth wear is more commonly used. When interpreting studies from different parts of the world, some consideration of these subtle differences should be understood. The major difference seems to be the impact of attrition. For many clinical situations, the impact of wear on the teeth is a combination of attrition and erosion particularly on the incisal or occlusal surfaces of teeth (Figs. 1 and 2) [10]. On the buccal or lingual surfaces, erosion is usually more dominant, but the impact of abrasion should not be forgotten. Since it is almost impossible to tell from the appearance of a lesion what is the underlying cause, it maybe more correct to use the term tooth wear. But there are circumstances in which one cause, more commonly erosion, is the dominant feature. Although the definitions of tooth wear and erosion are quite different, they can often be used to describe the same process.

\section{Prevalence}

Tooth wear indices grade the severity of wear by recording the surface characteristics of teeth with a numerical score. These data can be used to compare wear rates between individuals and between different populations. However, there is currently no agreed consensus on a universally

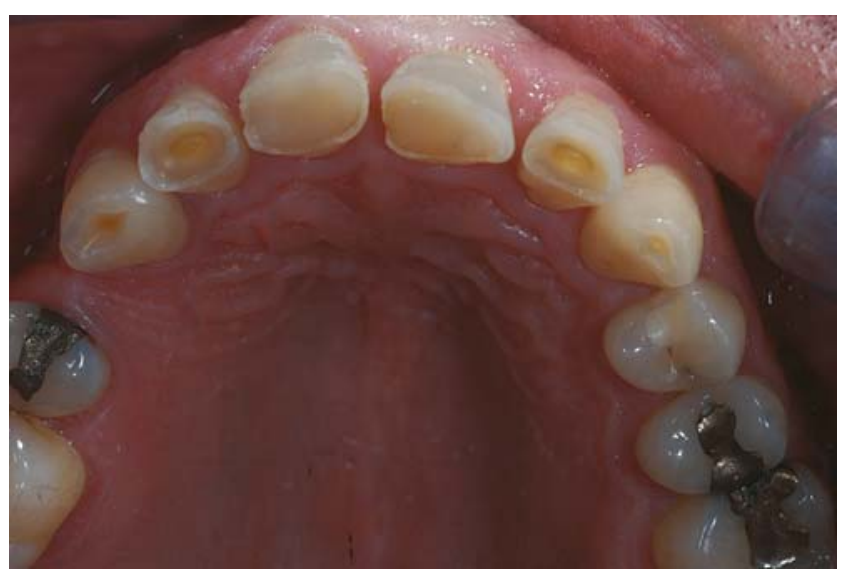

Fig. 1 The wear on the occlusal/incisal surfaces of the upper anterior teeth. The wear is caused by a combination of erosion and attrition. The "cupped out or ditched" areas result from the action of acids, whereas the flatter surfaces are caused by attrition

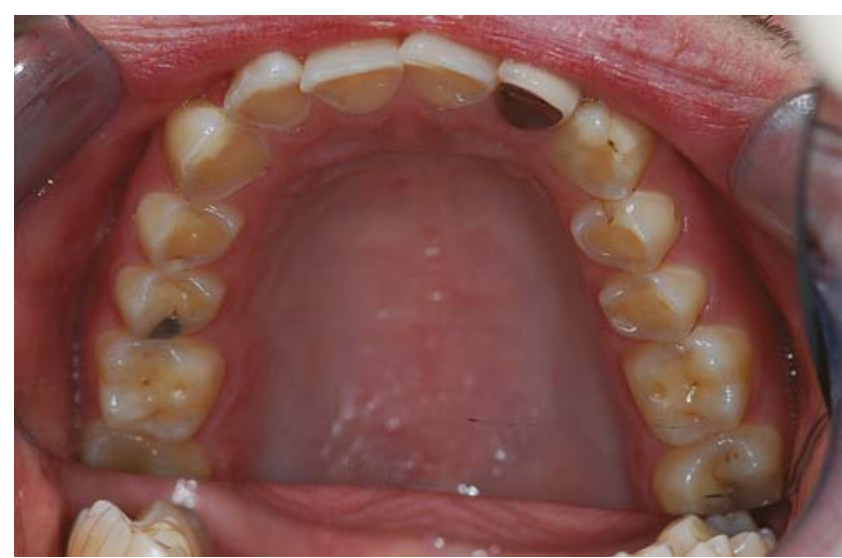

Fig. 2 The wear on the palatal/lingual surfaces of the teeth has been caused by regurgitation erosion. It is unlikely that abrasion or attrition has contributed to the process

accepted tooth wear index. Some indices [20,24] appear to be more widely used than others, but even these have undergone many modifications since they were first published [22]. For the most part, indices record wear on all tooth surfaces: cervical, buccal, occlusal/incisal and palatal/lingual [24]. The Smith and Knight index [24] records wear on all surfaces, but no attempt is made to relate the aetiology to the outcome of the wear on the teeth. Smith and Knight and later Robb and Smith estimated acceptable levels of wear in each age cohort [23, 25].

For the majority of the population, any wear on teeth is often limited to enamel, and dentine involvement only occurs in a relatively small proportion of the population [25]. A study by Dugmore and Rock [17] reported that $59.7 \%$ of 1,75312 -year-old children had evidence of tooth wear of which $2.7 \%$ had exposed dentine and this rose to $8.9 \%$ by the age of 14 years. Another study by Bardsley et al. [3] reported that $53 \%$ of 2,385 14-year-old adolescents had exposed dentine, but this included assessment of incisal surfaces. This latter study reported higher values in contrast to most other studies $[1,7]$. From most of these studies, it is clear that in children and adolescents wear of enamel is common, almost normal, but wear of dentine exposing more than $1 / 3$ of the tooth surface is less so.

Smith and Robb observed that tooth wear in adults was an almost universal experience with up to $97 \%$ of all ages experiencing some wear on their teeth with the older aged cohorts, dentine exposure became more common [25]. In their study, Smith and Robb [25] identified that between 5$7 \%$ of 1,007 adults had wear that could justify treatment, in all age cohorts. This is the only study published to date, with a large sample, which provides data on tooth wear in all age groups in adults. Other studies have reported the levels in specific age cohorts [20]; Donachie and Walls [14] reported the degree of tooth wear in a sample of 586 adults aged 45 and over in Newcastle, UK and reported no correlation between severity of wear and age. The data 
available to guide our knowledge on the levels of tooth wear in adults are therefore limited.

\section{Progression of tooth wear}

The term pathological tooth wear has been used to describe unacceptable levels of wear $[18,23,25]$. It is usually interpreted as meaning a level of wear that could justify operative treatment. However, finding a scientific way to interpret this concept is challenging. For pathological tooth wear to have meaning, the normal levels in different age groups are required to allow comparison, but the basic information on the pathogenesis of tooth wear is unknown. For instance, it is not known if tooth wear is episodic or continual throughout life. A few authors have reported data from longitudinal studies on adolescents and adults that indicate the development of new lesions $[16,19]$. Lussi et al. [20] reported the results of a prevalence study on 26-30and 46-50-year-old Swiss adults. In a later study, the same group of researchers reported the progression of wear in the same subjects over a 6-year period [19] and observed that wear progressed on the facial, occlusal and cervical surfaces and was more common in the older aged groups. However, the authors made no attempt to define what level of tooth wear was acceptable and what was not. Other studies have reported increase in the incidence of tooth wear in adolescents [16], but longitudinal data remain sparse.

There are no studies that report the progression of the same lesion within the same subject apart from one study which used a tooth wear index to record wear on study models taken from the subject's teeth [5]. They observed that only $7 \%$ of tooth surfaces showed any change over a median time of 26 months (IQR 14-50 months). The paucity of data on the severity of tooth wear in different age groups and its progression means it is difficult to be able to predict what is the pathophysiological behaviour of tooth wear.

A number of authors have published methods to measure tooth wear and erosion using profilometric scanners to accurately map teeth $[2,13,21,28]$. But these methods have reported their findings on relatively small numbers, and the methods are as yet unsuitable for larger studies. Often the time needed to scan a single tooth can take up to one hour and therefore they remain research tools for small studies. However, data from these studies suggest that wear on teeth may progress between $3.7 \mu \mathrm{m}$ at 6 months [6] and $5.56 \mu \mathrm{m} /$ month [21] to $18.3 \mu \mathrm{m} /$ month [28]. There are no data to indicate if particular teeth or tooth surfaces have a greater potential to wear or whether abrasion, attrition or erosion is more important in the progression. Furthermore, correlating this rather limited data to the general population is not possible, and therefore, most researchers rely upon epidemiological studies to record the severity of wear.

\section{Pathological tooth wear}

The concept that an unacceptable level of wear for a particular age group was first proposed by Eccles, Smith and others $[18,23,25]$. These and other authors argued that tooth wear continued throughout life as it was part of a normal physiological process. Berry and Poole [11, 12] hypothesised that in common with other mammals, humans have compensatory mechanisms that adapt to wear of teeth. They based their argument on comparative anatomy of mammals, in particular large herbivores, and suggested that tooth wear was beneficial to the efficiency of mastication. A gradual reduction in height and shape of cusps on molar teeth, they argued, led to improved masticatory efficiency. Their hypothesis remains unique and unproven but raises a number of interesting concepts.

Smith and coworkers [23, 27] introduced the term unacceptable levels of wear and later re-termed it as pathological tooth wear. The authors estimated unacceptable levels of wear based on their clinical judgement. Their so-called threshold levels were calculated for different age groups and used as an indicator for the necessity of operative intervention. However, these thresholds were judgements made by the authors, albeit based on clinical experience and previous research [25]. Smith and Robb [25] reported in their paper that the ultimate decision on the threshold values was the clinical experience of the first author. The data were analysed and re-analysed until the results matched the clinical judgement of the authors. Whilst this empirical assessment may have had some value at the time of publication, the ability to reproduce agreed thresholds in subsequent investigations would be challenging and have not been wholeheartedly supported by other researchers. Donachie and Walls [15] argued strongly that the threshold levels set for older age groups were inaccurate as they were based on a relatively small sample and so in their 1996 paper modified values were used [25].

We cannot rely upon the clinical judgement of one or two researchers to define what are pathological levels of tooth wear. Scientists need to have more defined and reproducible values. There are emerging data to suggest that tooth wear is common in all age groups [3, 17, 20, 25]. Smith and Robb [25] reported in their study of 1,007 subjects, aged 16 and over, that within each age cohort a proportion had higher grades of tooth wear [mean 5.1\%] than the others. Virtually every other study on the prevalence of tooth wear also reports that a small proportion, generally between $2 \%$ and $10 \%$, have higher levels of tooth wear than the majority. If these data are 
representative of the population at large, it is possible that a percentage of each age cohort has higher than normal levels of wear and this could be termed pathological.

The hypothesis that pathological tooth wear is age related depends on who is assessing the impact. State health care authorities, private insurance schemes, industry, dentists and patients all have different interpretations on what is pathological and what is not. For patients, loss of enamel could be considered pathological particularly if they are focussed upon the appearance of their teeth, whereas dentists may consider intervention is needed when dentine is involved, but their capacity to treat is affected by the limitations of restorative materials. On the other hand, state health care providers may take a much longer term view, with the assumption that a tooth remains functional, if not aesthetic, when operative care is not imperative.

Based on the current data, it is too challenging to suggest that tooth wear is an age-related phenomenon. There is some justification to this hypothesis based on the current data from children, adolescents and adults. Clinical experience suggests that as adults age they tend to develop more wear on the occlusal and incisal surfaces of teeth. It is likely, therefore, that some progression of wear on teeth is age related. However, this assumption needs investigating. Evidence partly from prevalence studies and partly from accurate measurement of tooth wear by profilometry tends to give support to this hypothesis. It must be remembered, however, that the prevalence studies at best report on just over 1,000 subjects. This is extremely small considering the populations involved. Tooth wear indices remain the most convenient and reproducible method to grade severity but are limited by incompatible criteria. It is imperative that a consensus is developed to build a simple and reproducible index, used by researchers so that data on the prevalence of tooth wear, particularly in adults, can be investigated.

\section{Conclusion}

The physiological wear of teeth is probably an age-related phenomenon. As the teeth continue to function and be challenged by erosive, attritive and abrasive factors, there will be change to the surfaces of teeth. This is most commonly seen on the incisal edges of the upper and lower incisors. As the challenges continue throughout life, it is not surprising therefore to see, as reported in Smith and Robb's study, that most people have some evidence of wear [25]. Therefore, small changes or evidence of gradual wear throughout life is probably a feature of the ageing of the dentition.

When pathological levels of wear are considered, the situation is less clear. There are insufficient data from epidemiological studies on adults to be definitive. But where data are present, it suggests similar proportions of severe levels of wear are observed in each age group, and it could be argued that this was independent of age [3, 17, 25]. It seems, therefore, that although tooth wear is an agedependant phenomenon, severe tooth wear is not.

Conflict of interest statement We declare that we have no conflict of interest.

\section{References}

1. Al Dlaigan YH, Shaw L, Smith A (2001) Dental erosion in a group of British 14-year-old, school children. Part I: Prevalence and influence of differing socioeconomic backgrounds. Br Dent $\mathrm{J}$ 190:145-149

2. Azzopardi A, Bartlett DW, Watson TF, Sherriff M (2004) The surface effects of erosion and abrasion on dentine with and without a protective layer. Br Dent J 196:351-354

3. Bardsley PF, Taylor S, Milosevic A (2004) Epidemiological studies of tooth wear and dental erosion in 14-year-old children in North West England. Part 1: The relationship with water fluoridation and social deprivation. Br Dent J 197:413-416

4. Bartlett D (2006) Intrinsic causes of erosion. Monogr Oral Sci 20:119-139

5. Bartlett DW (2002) Long term monitoring of tooth wear with study casts. Caries Res 36:174-222

6. Bartlett DW, Blunt L, Smith BGN (1997) Measurement of tooth wear in patients with palatal erosion. Br Dent J 182:179-184

7. Bartlett DW, Coward PY, Nikkah C, Wilson RF (1998) The prevalence of tooth wear in a cluster sample of adolescent schoolchildren and its relationship with potential explanatory factors. Br Dent J 184:125-129

8. Bartlett DW, Phillips KM, Smith BGN (1999) A difference of perspective - the North American and European interpretations of tooth wear. Int J Prosthodont 12:401-408

9. Bartlett DW, Shah P (2006) A critical review of non-carious cervical (wear) lesions and the role of abfraction, erosion, and abrasion. J Dent Res 85:306-312

10. Bartlett DW, Smith BGN (2000) Definition, classification and clinical assessment of attrition, erosion and abrasion of enamel and dentine. In: Addy M, Embery G, Edgar WM, Orchardson R (eds) Tooth wear and sensitivity - clinical advances in restorative dentistry. 1st edn. Martin Dunitz, London, pp 87-93

11. Berry DC, Poole DFG (1974) Masticatory function and oral rehabilitation. J Oral Rehabil 1:191-205

12. Berry DC, Poole DFG (1976) Attrition: possible mechanisms of compensation. J Oral Rehabil 3:201-206

13. Chadwick RG, Mitchell HL, Cameron I, Hunter B, Tulley M (1997) Development of a novel system for assessing tooth and restorations wear. J Dent 25:41-47

14. Donachie MA, Walls AW (1995) Assessment of tooth wear in an ageing population. J Dent 23:157-164

15. Donachie MA, Walls AWG (1996) The tooth wear index: a flawed epidemiological tool in an ageing population group. Community Dent Oral Epidemiol 24:152-158

16. Dugmore CR, Rock WP (2003) The progression of tooth erosion in a cohort of adolescents of mixed ethnicity. Int J Paediatr Dent 13:295-303

17. Dugmore CR, Rock WP (2004) The prevalence of tooth erosion in 12-year-old children. Br Dent J 196:279-282

18. Eccles JD (1982) Erosion affecting the palatal surfaces of upper anterior teeth in young people. Br Dent J 152:375-378 
19. Lussi A, Schaffner M (2000) Progression of and risk factors for dental erosion and wedge-shaped defects over a 6-year period. Caries Res 34:182-187

20. Lussi A, Schaffner M, Holtz P, Suter P (1991) Dental erosion in a population of Swiss adults. Community Dent Oral Epidemiol 19:286-290

21. Mitchell HL, Chadwick RG, Ward S, Manton SL (2003) Assessment of a procedure for detecting minute levels of tooth erosion. Med Biol Eng Comput 41:464-469

22. Moazzez R, Anggiansah A, Bartlett DW (2005) The association of acidic reflux above the upper oesophageal sphincter with palatal tooth wear. Caries Res 39:475-478

23. Smith BG, Knight JK (1984) A comparison of patterns of tooth wear with aetiological factors. Br Dent J 157:16-19
24. Smith BG, Knight JK (1984) An index for measuring the wear of teeth. Br Dent J 156:435-438

25. Smith BG, Robb ND (1996) The prevalence of toothwear in 1007 dental patients. J Oral Rehabil 23:232-239

26. Smith BGN (1989) Toothwear: aetiology and diagnosis. Dent Update 16:204-213

27. Smith BGN, Bartlett DW, Robb ND (1997) The prevalence, etiology and management of tooth wear in the United Kingdom. J Prosthet Dent 78:367-372

28. Sundaram G, Watson T, Bartlett D (2007) Clinical measurement of palatal tooth wear following coating by a resin sealing system. Oper Dent (in press)

29. Zero DT (1996) Etiology of dental erosion — extrinsic factors. Eur J Oral Sci 104:162-177 